\title{
Autoridades de transporte terrestre de pasajeros en el contexto de la conurbación: una necesaria visión regional de la actividad en el ejercicio de las competencias**
}

\section{Land passenger transport authorities in the conurbation context: A necessary regional vision of the activity in the exercise of competences}

SUMARIO

Introducción. I. El servicio público esencial de transporte. Un asunto nacional con amplio impacto y desarrollo en el nivel territorial. A. Autonomía territorial. B. El servicio público de transporte. Satisfacción de un interés que concurre en el nivel territorial y nacional. II. Marco de competencias para la organización del transporte terrestre en el régimen legislativo y reglamentario general. A. Otras autoridades y competencias relevantes en materia de transporte. III. La organización del transporte en el entorno regional. A. Condiciones para el ejercicio de las competencias en materia de transporte. B. Instrumentos para soluciones regionales de transporte. IV. Autoridad regional de transporte. Algunas reflexiones.

* Abogado, especialista en Responsabilidad Civil y Daño Resarcible, especialista internacional en Derecho del Transporte y magíster en Derecho Comercial. En el sector privado se ha desempeñado como asesor de empresas de transporte y consultor externo de firmas especializadas. En el sector público se ha desempeñado en el Ministerio de Transporte como asesor del Viceministerio de Transporte y como Subdirector de Transporte, Subdirector de Tránsito y Director de Transporte y Tránsito encargado, y en la Organización Internacional del Trabajo como colaborador externo experto en transporte. Actualmente es docente investigador del Centro de Estudios de Derecho del Transporte de la Universidad Externado de Colombia y consultor del sector transporte. Contacto: email andresf.lopez@uexternado.edu.co

** Recibido el: 3 de agosto de 2015, aprobado el: 12 de octubre de 2015.

Para citar el artículo: A. F. LóPEz GómEZ, Autoridades de transporte terrestre de pasajeros en el contexto de la conurbación: una necesaria visión regional de la actividad en el ejercicio de las competencias, Derecho del Estado n. ${ }^{\circ} 35$, Universidad Externado de Colombia, julio-diciembre de 2015, pp. 65-100. DOI: http://dx.doi.org/10.18601/01229893.n35.04 
RESUMEN

En este documento, conscientes de que las necesidades de movilización de las personas solo pueden ser adecuadamente satisfechas en una concepción integrada de los servicios de transporte -la que conlleva una visión regional de la actividad que no desconozca la autonomía de las entidades territoriales-, nos aproximamos a las competencias que para la organización del transporte han sido dispuestas en estos contextos. En esta tarea, luego de un breve recuento de las implicaciones del principio de autonomía territorial, se describe la clasificación que ha recibido el interés que en la actividad de transporte se ve involucrado, con base en el cual se han distribuido las competencias que enseguida dibujamos y respecto de las cuales, finalmente, abordamos las condiciones que para su ejercicio se imponen en dirección a la articulación regional de los servicios. Lo anterior nos permite fijar una posición en relación con la autoridad regional de transporte, recientemente dispuesta en el artículo 183 de la Ley 1753 de 2015.

\section{PALABRAS CLAVE}

Derecho de los transportes, reglamentación del transporte, autorización de transporte, reparto de competencias, competencia administrativa.

\section{SUMMARY}

Introduction. I. The essential transportation public service. A national issue with broad impact and development in a territorial level. A. Territorial autonomy. B. The public transportation service. Satisfaction concurring interest in the local and national territory. II. framework of the organization of land transport in the legislative regime and the general regulations. A. Other relevant authorities and responsibilities of transport. III. The transport organization in the regional enviroment. A. Conditions for the exercise of powers in transportation. B. Instruments for regional transportation solutions. IV. Regional Transportation Authority. Other considerations.

\section{ABSTRACT}

In this document, aware that the needs of mobilizing people can be adequately met in an integrated transport services conception - which involves a regional visión of the activity, that does not left unknow the autonomy of the territorial entities - we approach the proficiency that in order to achieve organized transportation have been arranged in these contexts. In this area, 
after a brief explanation of the implications of the territorial autonomy principle, its described the classification that has had the interest involved in the transport activity, based on which the competences have been distributed, we'll finally approach the conditions that for its exercise are imposed towards regional coordination of services. All of this allows us to establish a position in relation to the regional transport authority, recently established in Article 183 of Law 1753 of 2015.

\section{KEYWORDS}

Transport law, transport regulations, transport authorization, division of powers, administrative power.

\section{INTRODUCCIÓN}

Muy temprano se refirió la Corte Constitucional al servicio público de transporte y su importancia para el cumplimiento de los fines del Estado, llegando a afirmar que "La administración equilibrada y justa de la riqueza puede verse afectada por errores o falta de planeación del transporte público, el que siendo un instrumento clave del desarrollo, tiene una incidencia directa sobre el goce efectivo de los derechos fundamentales" ${ }^{1}$. Pero la planeación y desarrollo de la actividad adquirieron un grado adicional de dificultad cuando las concentraciones urbanas superaron la división político administrativa del país, que en vigencia del actual Estatuto del Transporte y respondiendo a la autonomía territorial constitucionalmente consagrada, había servido de principal marco de delimitación de competencia para la organización, control y vigilancia de la actividad transportadora.

La complejidad de las dinámicas urbanas, por su parte, hizo insuficientes algunas de las respuestas introducidas por la reglamentación de las modalidades de transporte, como fue el caso de las rutas de influencia consagradas en el artículos 35 del Decreto 170 de 2001 y en el artículo 41 del Decreto 171 del mismo año, hoy insertos en los artículos 2.2.1.1.8.1 y 2.2.1.4.6.7 del Decreto 1079 de 2015, normas con las que se pretendía, más allá de la división de competencias en atención al factor territorial, atender los servicios entre municipios contiguos que por encontrase sujetos a una influencia del orden poblacional, social y económica recíproca, requerían, para la satisfac-

1 Corte Constitucional. Sentencia T-604; Exp. T-4616, 14 de diciembre de 1992. M.P.: EDUARDO CIFUENTES MUÑOZ. En: http://www.corteconstitucional.gov.co/relatoria/1992/T-604-92. htm. 
ción adecuada de las necesidades de los usuarios, que las características del servicio se asemejaran a las de un servicio urbano.

La posibilidad de acudir a estas soluciones se encontró condicionada, en primer lugar, por la necesidad de un consenso entre las autoridades competentes en cada uno de los municipios involucrados, situación que finalmente reafirma la natural y continua sujeción a la autonomía territorial para la asignación de competencias en el transporte urbano.

En el contexto bosquejado, dentro de las bases del Plan Nacional de desarrollo 2014-2018, en el acápite de fortalecimiento institucional, se propuso, entre otros, "la creación de una Autoridad Única de Transporte en las aglomeraciones urbanas o en aquellos municipios cuya movilidad urbana se desarrolle más allá de sus propios límites jurisdiccionales", así como el diseño de "mecanismos de coordinación interinstitucional entre los distintos ámbitos espaciales: el urbano, metropolitano y el regional, con la participación de las entidades que lideran la planeación de los municipios y los encargados de formular y ejecutar proyectos de movilidad y transporte".

Esta autoridad única, en los términos propuestos, sería la "encargada de regular el servicio de transporte público de pasajeros, otorgar permisos y habilitaciones, integrar operacional y tarifariamente los diferentes modos, y garantizar la articulación de planes, programas y proyectos contenidos en los Planes Maestros de Movilidad de cada una de las ciudades, así como los incluidos en sus instrumentos de planeación territorial que influyan en la organización de la movilidad y el transporte".

Durante el trámite del proyecto de ley se registraron observaciones sobre el artículo que recogía dichas iniciativas, por considerarse violatorio de la autonomía territorial. Sin embargo, mediante la Ley 1753 del 8 de junio de 2015, por la cual se expide el Plan Nacional de Desarrollo 2014-2018, se recogió parcialmente lo propuesto, disponiendo, entre otros, que "El Gobierno Nacional, a solicitud de las entidades territoriales, podrá crear y fortalecer Autoridades Regionales de Transporte en las aglomeraciones urbanas o en aquellos municipios cuya movilidad urbana se desarrolle más allá de sus propios límites jurisdiccionales"2.

Lo anterior nos convoca al análisis del panorama de autoridades de transporte en los fenómenos de conurbación, en el cual partiremos del bosquejo del nivel de los intereses que se involucran en la actividad desde la perspectiva de la tensión entre autonomía territorial y Estado Unitario, para posteriormente dibujar el esquema de competencias para la organización del trans-

2 Congreso de la República. Ley 1753 (9 de junio de 2015). Por la cual se expide el Plan Nacional de Desarrollo 2014-2018 “Todos por un nuevo país”. Diario Oficial. Bogotá D.C., 2015, n. ${ }^{\circ} 49.538$. Artículo 183 . 
porte distribuidas en las diferentes autoridades en el contexto regional, para finalmente aproximarnos a las condiciones de su ejercicio en dicho entorno y las novedades o no que sobre el mismo introduce el nuevo texto normativo.

\section{EL SERVICIO PÚBLICO ESENCIAL DE TRANSPORTE. UN ASUNTO NACIONAL CON AMPLIO IMPACTO Y DESARROLLO EN EL NIVEL TERRITORIAL}

En vigencia de la Constitución Política de 1886, antes de la institucionalización del concepto de autonomía territorial en nuestra actual Carta Política de 1991, las funciones para la organización del transporte y la autorización de servicios fueron de manera general asignadas por los artículos $2 .^{\circ}$ y $8 .^{\circ}$ del Decreto 1393 de 1970 al Instituto Nacional de Transporte, lo que obviamente no impidió la atribución de algunas competencias particulares en esta materia a los entes territoriales, dentro del marco de una descentralización administrativa que, en opinión de la Corte Constitucional, "caracterizó los últimos decenios de vigencia de la Constitución de 1886"3.

El Instituto se suprimió con ocasión del proceso de reestructuración del sector transporte, ordenado en el Decreto 2171 de 1992, dictado con fundamento en la facultad otorgada por el artículo 20 transitorio de la Constitución Política de 1991, en particular podemos decir, entre otros, con el fin de atender "la redistribución de competencias [...] que ella establece"; verbigracia, la autonomía que para la gestión de sus intereses se concede a las entidades territoriales ${ }^{4}$.

Resulta entonces pertinente, de cara a los objetivos trazados, bosquejar los alcances de la autonomía territorial en general y enmarcar la actividad transportadora en el interés nacional y local.

\section{A. Autonomía territorial}

La autonomía de las entidades territoriales se ha desarrollado en una sana tensión formada a partir de su existencia en el marco de un Estado Unitario,

3 Corte Constitucional. Sentencia C-478; Exp. D-003, 6 de agosto de 1992. M.P.: EDUARDO CIFUENTES MUÑOZ. En: http://www.alcaldiabogota.gov.co/sisjur/normas/Norma1.jsp?i=5939.

4 Asamblea Nacional Constituyente. Constitución Política de Colombia. 1991. Artículo 287. "La Constitución de 1991 introdujo cambios fundamentales en el régimen territorial. Este pasó de un esquema con centralización política y descentralización administrativa, donde el énfasis estaba en lo nacional y la descentralización era una mera técnica de administrar, a un sistema de autonomía para las entidades territoriales sin perder de vista la unidad del Estado". Colombia. Corte Constitucional. Sentencia C-478; Exp. D-003, 6 de agosto de 1992. 
tensión que a su vez contribuye en la tarea de especificarla y delimitarla conceptualmente, valiéndose la jurisprudencia para el efecto de un sistema que se ha denominado de limitaciones recíprocas y que tiende a encontrar el equilibrio entre los mismos ${ }^{5}$.

Frente al equilibrio entre los conceptos de autonomía territorial y Estado Unitario, la Corte Constitucional, en sentencia C-535 de 1996, exp. D-1239, M.P.: Alejandro Martínez Caballero, afirmó: "El equilibrio entre ambos principios se constituye entonces a través de limitaciones. Por un lado, el principio de autonomía debe desarrollarse dentro de los límites de la Constitución y la ley, con lo cual se reconoce la posición de superioridad del Estado unitario, y por el otro, el principio unitario debe respetar un espacio esencial de autonomía cuyo límite lo constituye el ámbito en que se desarrolla esta última". Anteriormente la corporación había afirmado: "La autonomía es afirmación de lo local, seccional y regional, pero sin desconocer la existencia de un orden superior"'.

En la determinación de los alcances de uno y otro encontramos que de conformidad con lo establecido en el artículo 287 de la Carta Política, la autonomía encuentra una primera limitación en lo dispuesto por la misma Constitución, seguida por lo que al respecto disponga el legislador, lo que finalmente ha permitido afirmar que "la Carta Política no definió el grado de autonomía que le [sic] atribuyó a las entidades territoriales, delegando en el legislador tal competencia" entre la Nación y los entes territoriales es algo que el ordenamiento superior ha confiado"8 a este último.

Correspondiendo entonces al legislador la distribución de competencias y no encontrándose definido constitucionalmente el grado de autonomía de las entidades territoriales, es el legislador el llamado a procurar el equilibrio entre los principios de autonomía territorial y el concepto de Estado Unita-

5 Corte Constitucional. Sentencia C-100; Exp. D-9219, 27 de febrero de 2013. M.P.: Mauricio González Cuervo. En: http://www.corteconstitucional.gov.co/RELATORIA/2013/C-100-13 htm. Corte Constitucional. Sentencia C-579; Exp. D-3260 y D-3262, 5 de junio de 2001. M.P.: Eduardo Montealegre Lynett. En: http://www.alcaldiabogota.gov.co/sisjur/normas/Norma1. jsp?i=9622. Corte Constitucional. Sentencia C-072; Exp. D-9733, 4 de febrero de 2014. M.P.: Alberto Rojas Ríos. En: http://www.corteconstitucional.gov.co/relatoria/2014/C-072-14.htm.

6 Corte Constitucional. Sentencia C-478; Exp. D-003, 6 de agosto de 1992. Ob. cit.

7 Corte Constitucional. Sentencia C-1187; Exp. D-2854, 13 de septiembre de 2000. M.P.: Fabio Morón Díaz. En: http://www.alcaldiabogota.gov.co/sisjur/normas/Norma1.jsp?i=14655.

8 Corte Constitucional. Sentencia C-321; Exp. OP-120, 11 de mayo de 2009. M.P.: Humberto Antonio Sierra Porto. En: http://www.corteconstitucional.gov.co/RELATORIA/2009/C-321-09. htm. 
rio, razón por la cual es pertinente analizar los parámetros que este deberá considerar en ejercicio de su labor.

Partiremos para el efecto, como se anticipaba en la cita atrás transcrita, de la exposición de aquel espacio esencial de la autonomía territorial que el principio unitario debe respetar y que se ha encontrado en lo que al respecto ha determinado directamente la Constitución Política de Colombia, lo que permite inmediatamente concluir que dicho espacio o núcleo esencial de la autonomía territorial es indisponible por parte del legislador ${ }^{9}$.

Este núcleo esencial, como contenido mínimo, se encuentra en la lectura de lo dispuesto por el artículo 287 de la Constitución Política y se dirige a materializar el derecho que asiste a las entidades territoriales para gestionar sus propios intereses. Forman parte de este ${ }^{10}$ el derecho a gobernarse por autoridades propias, ejercer las competencias que les correspondan, administrar los recursos y establecer los tributos necesarios para el cumplimiento de sus funciones y participar de las rentas nacionales, "y el de que el órgano de representación más inmediato al pueblo participe en la toma de las principales decisiones para el desarrollo de la vida local" ${ }^{11}$; habiéndose sostenido que "La autonomía está además ligada a la soberanía popular y a la democracia participativa, pues se requiere una participación permanente que permita que la decisión ciudadana se exprese sobre cuáles son las necesidades a satisfacer y la forma de hacerlo" 12 .

Bosquejado el contenido mínimo, encontramos el correlativo que impone el principio unitario como parámetro máximo, dado al legislador en la configuración de la autonomía territorial, de acuerdo con el cual la autonomía territorial no podrá implicar la ruptura de la configuración del Estado, en una trasmutación del concepto hacia el de independencia.

9 Corte Constitucional. Sentencia C-535; Exp.D-1239, 16 de octubre de 1996. M.P.: Alejandro Martínez Caballero. En: http://www.corteconstitucional.gov.co/relatoria/1996/c-535-96. htm.

10 Corte Constitucional. Sentencia C-403; Exp. D-2324, 2 de junio de 1999. M.P.: Alfredo Beltrán Sierra. En: http://www.alcaldiabogota.gov.co/sisjur/normas/Norma1.jsp?i=5736. Corte Constitucional. Sentencia C-219; Exp. D-1444, 24 de abril de 1997. M.P.: Eduardo Cifuentes Muñoz. En: http://www.alcaldiabogota.gov.co/sisjur/normas/Norma1.jsp?i=3405. Corte Constitucional. Sentencia C-579; Expedientes D-3260 y D-3262, 5 de junio de 2001. Corte Constitucional. Sentencia C-931; Exp. D-6265, 15 de noviembre de 2006. M.P.: Rodrigo Escobar Gil. En: http://www.corteconstitucional.gov.co/relatoria/2006/C-931-06.htm. Corte Constitucional. Sentencia C-072; Exp. D-9733, 4 de febrero de 2014. M.P.: Alberto Rojas Ríos.

11 Corte Constitucional. Sentencia C-123; Exp. D-9700, 5 de marzo de 2014. M.P.: Alberto Rojas Ríos. En: http://www.corteconstitucional.gov.co/relatoria/2014/c-123-14.htm.

12 Corte Constitucional. Sentencia C-535; Exp. D-1239, 16 de octubre de 1996. M.P.: Alejandro Martínez Caballero. 
Los anteriores, operando en el marco de los intereses propios de las entidades territoriales, como lo expone el precepto constitucional, impiden que la sola invocación del Estado Unitario permita otorgarle competencia al nivel central sobre asuntos que no trascienden el contexto municipal o regional ${ }^{13}$. Ahora, no se desconoce con lo anterior la posibilidad de que un interés local concurra con uno de orden nacional de mayor relevancia, caso en el cual del principio unitario pueden desprenderse "intervenciones puntuales, que desplacen, incluso, a las entidades territoriales en asuntos que de ordinario se desenvuelven en la órbita de sus competencias"14.

Los anteriores, como principios constitucionales, pueden encontrar desarrollo en diferentes grados -desarrollo que corresponde al legislador procurar a través de la regulación lega ${ }^{15}$ y en cuyo ejercicio deberá observar los límites mínimos y máximos atrás expuestos-, los que comúnmente resultan definidos en temáticas puntuales a través de la mayor realización de uno, en sacrificio parcial del otro. De lo que directamente se desprende la exigencia de razonabilidad y proporcionalidad de las limitaciones ${ }^{16}$.

Así, unos serán los alcances de la autonomía territorial en los asuntos estrictamente locales o del resorte exclusivo de la entidad territorial y otros, en aquellos en los cuales concurre con este un interés nacional. En lo que a este caso corresponde, la Corte Constitucional sostuvo que "la comunidad humana dentro del Estado está constituida por diversos intereses, y su bienestar se logra por multiplicidad de acciones que encuentran su unidad en

13 Corte Constitucional. Sentencia C-894; Exp. D-4552, 7 de octubre de 2003. M.P.: Rodrigo Escobar Gil. En: http://corteconstitucional.gov.co/relatoria/2003/C-894-03.htm. Corte Constitucional. Sentencia C-149; Exp. D-7828 y D-7843, 4 de marzo de 2010. M.P.: Jorge Iván Palacio Palacio. En: http://www.corteconstitucional.gov.co/RELATORIA/2010/C-149-10. htm. Corte Constitucional. Sentencia C-072; Exp. D-9733, 4 de febrero de 2014. M.P.: Alberto Rojas Ríos.

14 Corte Constitucional. Sentencia C-149; Expedientes D-7828 y D-7843, 4 de marzo de 2010. En salvamento de voto a la sentencia C-219 de 1997, el magistrado Hernando Herrera Vergara afirmó: "Si bien es cierto que el legislador debe respetar el reducto mínimo de la autonomía dentro de cuyo ámbito se encuentra el derecho de las entidades territoriales a administrar sus propios recursos, como se expresa en la sentencia mencionada, ello no es óbice para que no se pueda entender que el legislador sí está autorizado para intervenir en la gestión de los intereses propios de esas entidades, como en aquellas situaciones inherentes a la finalidad social del Estado, que versan sobre el bienestar general y el mejoramiento de la calidad de vida de la población".

15 "Regulación que corresponde, no como permiso sino como deber, al legislador, el cual está en libertad de configurarla para que surta los efectos pretendidos por la Constitución".

16 Corte Constitucional. Sentencia C-579; Exp. D-3260 y D-3262, 5 de junio de 2001. Corte Constitucional. Sentencia C-894; Exp. D-4552, 7 de octubre de 2003. Corte Constitucional. Sentencia C-123; Exp. D-9700, 5 de marzo de 2014. M.P.: Alberto Rojas Ríos. En: http://www. corteconstitucional.gov.co/relatoria/2014/c-123-14.htm. 
la generalidad de la ley. De ahí que es un desorden el pretender que lo que por esencia es nacional se regule con criterios seccionales o locales" ${ }^{17}$. Lo anterior no conlleva la negación de la posibilidad de que en determinadas circunstancias la regulación legal sea ampliada e imponga mayores o más rigurosas exigencias en el ámbito territorial, en atención a los intereses locales concurrentes ${ }^{18}$.

De manera particular consideramos que los intereses que se ven involucrados en el servicio público de transporte son de esta última clase, es decir, de aquellos que concurren en el nivel central y local, como a continuación pasamos a exponer.

\section{B. El servicio público de transporte. Satisfacción de un interés que concurre en el nivel territorial y nacional}

La actividad transportadora no fue siempre concebida como servicio, fue solo en 1954 que, mediante el Decreto extraordinario 826, el transporte de personas en vehículos automotores por retribución fue considerado un servicio público ${ }^{19}$, más allá de la actividad comercial que desde el Código de Comercio Terrestre se regulaba. Legislativamente se consagró su carácter esencial en los artículos 5. y 56 de la Ley 336 de 1996.

La Corte Constitucional no ha vacilado al momento de reconocer la trascendencia de la actividad, y en sentencia T-595 de $2002^{[20]}$ lo calificó como un servicio "inherente a la finalidad social del Estado", afirmando que "La posibilidad de generar procesos de desarrollo económico e integración social que propicien el goce efectivo de las garantías constitucionales, reposa, en gran medida, en el éxito de los sistemas de transporte público".

Como en otra oportunidad tuvimos la oportunidad de concluir, la importancia de la actividad encuentra asimismo un impacto directo en los individuos y particularmente en la posibilidad de procurarse un goce efectivo de los derechos fundamentales que les son connaturales, pues, como lo sostuvo

17 Corte Constitucional. Sentencia C-216; Exp. D-435, 28 de abril de 1994. M.P.: Vladimiro Naranjo Mesa. En: http://www.corteconstitucional.gov.co/relatoria/1994/C-216-94.htm.

18 Corte Constitucional. Sentencia C-535, Exp. D-1239, 16 de octubre de 1996. M.P.: Alejandro Martínez Caballero. Sentencia C-535 de 1996.

19 Decreto Extraordinario 826 de 1954, artículo 3..: "el transporte de personas y mercadería en vehículos automotores, mediante retribución en dinero, es un servicio público y su organización y control, corresponde al gobierno".

20 Corte Constitucional. Sentencia T-595; Exp. T-444377, 1 de agosto de 2002. M.P.: Manuel José Cepeda Espinosa. En: http://www.corteconstitucional.gov.co/relatoria/2002/t-595-02 . htm. 
la Corte Constitucional en sentencia T-604 de 1992 2 [21], "De la capacidad efectiva de superar distancias puede depender la estabilidad del trabajo, el acceso y la permanencia en el sistema educativo, el ejercicio de la iniciativa privada y, en general, el libre desarrollo de la personalidad"; considerándose por tanto y en consecuencia que, "A nivel del individuo, el transporte es un instrumento de efectividad de los derechos fundamentales". Y en un contexto general concluía que "La administración equilibrada y justa de la riqueza puede verse afectada por errores o falta de planeación del transporte público".

La importancia del servicio público de transporte en la materialización del derecho constitucional de locomoción ha estado presente en los pronunciamientos de la Corte Constitucional, y es así como en sentencia T-595 de 2002 comentaba esta corporación:

Desde sus inicios, la jurisprudencia constitucional ha señalado que la libertad de locomoción [...] [s]e trata de un derecho constitucional que al igual que el derecho a la vida, tiene una especial importancia en tanto que es un presupuesto para el ejercicio de otros derechos y garantías, como por ejemplo, el derecho a la educación, al trabajo o a la salud. [...] Ahora bien, la jurisprudencia constitucional ha considerado que en el contexto urbano el servicio de transporte público es un medio indispensable para poder ejercer la libertad de locomoción.

Esta relevancia de la actividad, que con toda contundencia evidencia el carácter nacional de los intereses que en su contexto se involucran, se configura en criterio para la evaluación de la racionalidad y la proporcionalidad de la intervención en la autonomía territorial, que se materializa en la medida en que se disponga en la regulación nacional de la actividad, que por mandato del numeral 23 del artículo 150 de la Constitución corresponde al Congreso de la República al tratarse de un servicio público.

Y decimos intervención en la autonomía territorial por cuanto el interés nacional en la actividad, de superior entidad, no desdibuja la existencia de un interés local atado al desarrollo de la actividad, entre múltiples razones, por la directa incidencia de la misma en la gestión municipal.

En este contexto, como se manifestaba de manera general en la sentencia C-149 de 2010, debemos recordar que "la centralización política [...] por un lado, exige unidad en todos los ramos de la legislación, exigencia que se traduce en la existencia de parámetros uniformes del orden nacional y de unas competencias subordinadas a la ley en el nivel territorial y, por otro, la existencia de competencias centralizadas para la formulación de decisiones

21 Corte Constitucional. Sentencia T-604; exp. T-4616, 14 de diciembre de 1992. M.P.: Eduardo Cifuentes Muñoz. 
de política que tengan vigencia para todo el territorio nacional"; sin olvidar, como se afirma en la misma providencia, que "corresponde al legislador establecer las condiciones básicas de la autonomía y definir, respetando el principio de subsidiariedad, las competencias del orden nacional que deberán desarrollarse conforme al principio de coordinación, que presupone unas reglas uniformes y una pautas de acción que, sin vaciar de contenido el ámbito de autonomía territorial, permitan una armonización de funciones".

El éxito en estas labores resulta fundamental para viabilizar la satisfacción adecuada de las necesidades de movilización de los usuarios, pues los intereses locales y nacionales no solo confluyen en un espectro político-administrativo, sino también en el nivel operativo. Ya veremos, al dibujar el panorama de competencias para la organización del transporte, la incidencia del concepto de ruta, entendido como el trayecto comprendido entre un origen y un destino, y cómo este supera en ocasiones el nivel municipal e incluso el departamental, configurándose estas operaciones en un servicio ofrecido en el perímetro de transporte nacional. Sin embargo, es indudable que las necesidades de desplazamiento de los habitantes de la urbe contemporánea, desde un punto de vista fenomenológico y en la concepción del servicio que se dirige a su satisfacción, superan la estricta sujeción a la ruta como elemento determinante del entorno del desplazamiento del usuario, porque actualmente no suele encontrarse en una ruta la plena satisfacción del requerimiento de movilización de los ciudadanos, o difícilmente se viabiliza esta en una concepción individual y asilada ${ }^{22}$; imponiéndose por lo tanto la necesidad de estructuración de los servicios de transporte como sistemas, llamados a integrarse entre sí y complementarse; aproximación que viene, desde al menos dos lustros, ganando terreno en el Plan Nacional de Desarrollo ${ }^{23}$ y que afirma el interés nacional en la organización de la actividad.

Sentados estos antecedentes, nos corresponde ahora abordar las disposiciones que con anterioridad a la consagración legislativa de la autoridad regional de transporte procuraban el equilibrio o la armonización entre el principio unitario y el autonómico en la distribución de competencias para la organización del transporte en el entorno regional; para lo cual debemos introducirnos

22 Dada la diversidad de orígenes y destinos de los usuarios y en atención a la superposición que muchos de ellos generarían en las rutas trazadas, desde el punto de vista de la eficiencia y en atención a la capacidad limitada de la infraestructura, resulta actualmente inviable la atención de estas necesidades sin transbordos en un porcentaje importante de los desplazamientos dentro de los grandes centros urbanos.

23 Para el efecto, basta mirar el parágrafo 7 del artículo 132 de la Ley 1450 de 2011, modificado por el artículo 32 de la Ley 1753 de 2015 y el artículo 52 de la Ley 1151 de 2007. 
un poco en las competencias que para la organización del transporte se han otorgado a las diferentes entidades del nivel territorial y regional.

\section{MARCO DE COMPETENCIAS PARA LA ORGANIZACIÓN}

DEL TRANSPORTE TERRESTRE EN EL RÉGIMEN LEGISLATIVO Y REGLAMENTARIO GENERAL

Para delimitar este primer y general marco de competencias para la organización del transporte, que como decíamos ha respondido a la división político-administrativa del Estado y a la autonomía que a sus entidades se otorgó por el constituyente, debemos remontarnos al concepto de actividad transportadora, recogido en el artículo 6. ${ }^{\circ}$ de la Ley 336 de 1996, de conformidad con el cual "Por actividad transportadora se entiende un conjunto organizado de operaciones tendientes a ejecutar el traslado de personas o cosas, separada o conjuntamente, de un lugar a otro"24. Ese desplazamiento entre dos lugares, uno de origen y otro de destino, por un trayecto determinado, donde encuentra su contenido el concepto de ruta recogido en las reglamentaciones de las modalidades sujetas a ellas ${ }^{25}$, independientemente de que el servicio de transporte se encuentre o no sujeto al mismo en su prestación, ha tradicionalmente permitido determinar un área geográfica dentro de la cual se desarrolla la actividad.

Atendiendo los anteriores factores, el artículo 11 de la Ley 105 de 1993 determina los perímetros dentro de los cuales se desarrolla la actividad transportadora, indicando al respecto:

Constituyen perímetros para el transporte nacional, departamental y municipal, los siguientes:

a. El perímetro del transporte nacional comprende el territorio de la Nación. El servicio nacional está constituido por el conjunto de las rutas cuyo origen y destino estén localizados en diferentes Departamentos dentro del perímetro nacional. No hacen parte del servicio nacional las rutas departamentales, municipales, asociativas o metropolitanas.

b. El perímetro del transporte departamental comprende el territorio del Departamento. El servicio departamental está constituido consecuentemente por el

24 Congreso de la República. Ley 336 (20 de diciembre de 1996). Por la cual se adopta el Estatuto Nacional de Transporte, Diario Oficial, n. ${ }^{\circ} 42948$. Artículo 6.

25 Presidente de la República. Decreto 170 (5 de febrero de 2001). Por el cual se reglamenta el servicio público de transporte terrestre automotor colectivo metropolitano, distrital y municipal de pasajeros, Diario Oficial, n. ${ }^{\circ} 44318$. Artículo 7. 
conjunto de rutas cuyo origen y destino estén contenidos dentro del perímetro Departamental.

No hacen parte del servicio departamental las rutas municipales, asociativas o metropolitanas.

c. El perímetro de transporte distrital y municipal comprende las áreas urbanas, suburbanas y rurales y los distritos territoriales indígenas de la respectiva jurisdicción ${ }^{26}$.

Definidos estos perímetros del transporte en función del origen y destino de las rutas, resulta intuitiva la lectura del artículo 8. ${ }^{\circ}$ de la Ley 336 de 1996, al establecer que "las autoridades que conforman el sector y el sistema de transporte serán las encargadas de la organización, vigilancia y control de la actividad transportadora dentro de su jurisdicción" ${ }^{27}$ • ¿Cuáles son esas autoridades?, el artículo 1. ${ }^{\circ}$ de la Ley 105 de 1993 señala que lo son, en general, las "dependencias de los sectores central o descentralizado de cualquier orden, que tengan funciones relacionadas con" 28 la actividad transportadora.

Sin perjuicio de las competencias generales de estas entidades, el marco de competencias descrito se delimita un poco más en el artículo 17 de la Ley 336 de 1996, cuando establece que "En el transporte de pasajeros será la autoridad competente la que determine la demanda existente o potencial, según el caso para adoptar las medidas conducentes a satisfacer las necesidades de movilización" 29 , recordándonos el artículo 58 de la misma disposición las consecuencias de desbordar los parámetros de jurisdicción previamente señalados ${ }^{30}$.

Ahora, en esa tarea que por disposición del numeral 11 del artículo 189 de la Constitución le corresponde al Presidente de la República, se expidieron los decretos reglamentarios de las modalidades de transporte terrestre y en ellos, con toda claridad, se mantiene el principio establecido en la fijación

26 Congreso de la República. Ley 336 (20 de diciembre de 1996). Artículo 11.

27 Ibíd., art. 8.

28 Congreso de la República. Ley 105 (30 de diciembre de 1993). Por la cual se dictan disposiciones básicas sobre el transporte, se redistribuyen competencias y recursos entre la Nación y las Entidades Territoriales, se reglamenta la planeación en el sector transporte y se dictan otras disposiciones, Diario Oficial, n. ${ }^{\circ}$ 42948. En: http://www.alcaldiabogota.gov.co/sisjur/normas/ Norma1.jsp?i=296. Artículo 1, inciso 2.

29 Congreso de la República. Ley 336 (20 de diciembre de 1996). Artículo 17.

30 "Las autoridades locales no podrán autorizar servicios regulares por fuera del territorio de su jurisdicción, so pena de incurrir en causal de mala conducta”: ibíd., art. 58. 
de los perímetros del transporte y la no subsunción del de mayor extensión territorial en el de menor.

Así, el Decreto 170 de 2001, "Por el cual se reglamenta el servicio público de transporte terrestre automotor colectivo metropolitano, distrital y municipal de pasajeros", unificado al interior del Decreto 1079 de 2015, al realizar la clasificación de la modalidad según el radio de acción, estableció que el metropolitano es aquel que se presta entre los municipios que conforman el área y el distrital o municipal, aquel que se presta dentro de la jurisdicción de un distrito o municipio"31. El Decreto 172 de 2001, por el cual se reglamenta el Servicio Público de Transporte Terrestre Automotor Individual de Pasajeros en Vehículos Taxi, integrado igualmente al decreto mencionado, mantiene idéntica redacción ${ }^{32}$.

En el Decreto 175 de 2001, "por el cual se reglamenta el Servicio Público de Transporte Terrestre Automotor Mixto" -y que en virtud de la unificación forma actualmente parte del Decreto Único del Sector-, sin entrar a diferenciar expresamente los radios de acción metropolitano, distrital y municipal, clasifica la actividad transportadora mixta según el radio éste en metropolitano, distrital o municipal y nacional o intermunicipal, refiriendo que la primera se configura "Cuando se presta entre municipios de un área metropolitana constituida por ley o dentro de la jurisdicción de un distrito o municipio [y la segunda] [...] Cuando se presta entre dos o más municipios que no hacen parte de un área metropolitana"33. El Decreto 171 de 2001, "Por el cual se reglamenta el Servicio Público de Transporte Terrestre Automotor de Pasajeros por Carretera" -hoy inserto en el Decreto 1079 de 2015-, estableció que "El radio de acción en esta modalidad será de carácter nacional. Incluye los perímetros departamentales y nacional" ${ }^{34}$.

Cualquier duda que quedare al respecto resulta disipada con la lectura de las autoridades competentes, que en atención a los decretos menciona-

31 Presidente de la República. Decreto 170 (5 de febrero de 2001). Artículo 2.2.1.1.1.1.

32 Presidente de la República. Decreto 172 (5 de febrero de 2001). Por el cual se reglamenta el Servicio Público de Transporte Terrestre Automotor Individual de Pasajeros en Vehículos Taxi, Diario Oficial, n. ${ }^{\circ}$ 44318. Artículo 24. Presidente de la República. Decreto 1079 (26 de mayo de 2015). Por medio del cual se expide el Decreto Único Reglamentario del Sector Transporte, Diario Oficial, n. ${ }^{\circ}$ 49523. Artículo 2.2.1.3.5.3.

33 Presidente de la República. Decreto 175 (5 de febrero de 2001). Por el cual se reglamenta el Servicio Público de Transporte Terrestre Automotor Mixto, Diario Oficial, n. ${ }^{\circ} 44318$. Artículo 9 y Presidente de la República. Decreto 1079. (26, mayo, 2015). Artículo 2.2.1.5.2.1.

34 Presidente de la República. Decreto 170 (5 de febrero de 2001). Ob. cit. Artículo 22; Presidente de la República. Decreto 171 (5 de febrero de 2001). Artículo 22 y Presidente de la República. Decreto 1079 (26 de mayo de 2015). Por medio del cual se expide el Decreto Único Reglamentario del Sector Transporte, Diario Oficial, n. ${ }^{\circ}$ 49523. Artículo 2.2.1.4.5.1. y Presidente de la República. Decreto 1079 (26 de mayo de 2015). Artículo 2.2.1.4.5.1. 
dos corresponde según el radio de acción. En este sentido, el Decreto 170 de 2001 establece: "Son autoridades de transporte competentes [...] En la jurisdicción nacional, el Ministerio de Transporte ${ }^{35}$. En la jurisdicción distrital y municipal, los alcaldes municipales y/o distritales o en los que estos deleguen tal atribución. En la jurisdicción del área metropolitana constituida de conformidad con la ley, la autoridad única de transporte metropolitano o los alcaldes respectivos en forma conjunta, coordinada y concertada" ${ }^{36}$; contenido normativo reproducido en los artículos $8 .^{\circ}$ del Decreto 172 de 2001 y 9. ${ }^{\circ}$ del Decreto 175 de 2001.

De esta manera vemos cómo, en el marco de la actividad transportadora, el origen y destino de la ruta como entorno del desplazamiento configura el perímetro del transporte y este, a su vez, define, por un factor que considera la autonomía territorial, la autoridad competente para la organización, vigilancia y control de la actividad transportadora; sin que, como decíamos, pueda entenderse alguna subsumida dentro de otra a la que pertenece.

Resulta necesario el énfasis en las competencias de organización, vigilancia y control, toda vez que, considerando lo dispuesto por los artículos 44 de la Ley 105 de 1993, 31 y 33 de la Ley 152 de 1994, numeral 1 del artículo $3 .^{\circ}$, numerales 2 y 9 del artículo $8 .^{\circ}$, numeral 2 del artículo 13, numeral 2.1 del artículo 16 de la Ley 388 de 1997 y artículos 1..$^{\circ}$ y 2. ${ }^{\circ}$ del Decreto 087 de 2011, entre otros, en materia de fijación de políticas y de planeación del transporte y la infraestructura para su desarrollo, intervienen otras autoridades.

Como puede verse, en principio la definición de la autoridad competente no resulta conflictiva entre municipios, distritos, departamentos y la Nación. Sin embargo, en los casos de conformación de áreas metropolitanas se ha pretendido introducir alcances inaceptables, como consecuencia de una lectura inadecuada de las competencias a ellas otorgadas por la Ley 1625 de 2013, y particularmente por las disposiciones que a continuación se enuncian.

El artículo 5. . de la Ley 1625 refiere que "La jurisdicción del Área Metropolitana corresponde a la totalidad del territorio de los municipios que la conforman" 37 . Posteriormente, señala el artículo 6. ibíd. que "Son competencias de las Áreas Metropolitanas sobre el territorio puesto bajo su jurisdicción, además de las que les confieran otras disposiciones legales, '...$b)$

35 Para este caso, encontramos igualmente que de conformidad con el artículo 57 de la Ley 336 de 1996, "cuando el servicio sea intermunicipal, será competencia del Ministerio de Transporte".

36 Decreto 170 de 2001, art. 2.2.1.1.2.1.

37 Congreso de la República. Ley 1625 (29 de abril de 2013). Por la cual se deroga la Ley Orgánica 128 de 1994 y se expide el Régimen para las Áreas Metropolitanas, Diario Oficial, n. ${ }^{\circ}$ 48776. Artículo 5. 
Racionalizar la prestación de servicios públicos a cargo de los municipios que la integran $[\ldots]$ p) Planificar la prestación del servicio de transporte público urbano de pasajeros..." 38 .

Las anteriores, aunadas a la consideración de las funciones de las áreas

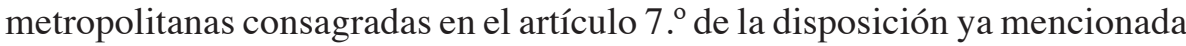
$-v . g r .$, "f) Coordinar, racionalizar y gestionar los servicios públicos de carácter metropolitano [...] o) Formular y adoptar instrumentos para la planificación y desarrollo del transporte metropolitano [...] p) Planificar la prestación del servicio de transporte público urbano de pasajeros..." ${ }^{39}$-, llevaron a algunos a afirmar que ante la existencia de autoridad metropolitana desaparecían las competencias de la autoridad municipal en estas materias.

Sin embargo, una conclusión semejante no solo obviaba el hecho de que dichas funciones encontraban desarrollados sus alcances dentro del mismo texto legal en unas condiciones que distaban mucho de las pretendidas ${ }^{40}$, sino que también pasaba por alto que cada una de las funciones correspondientes al área metropolitana se establecían, de manera expresa en algunas, tácita en otras, dentro del marco de sus competencias, y que sin perjuicio de lo establecido en el parágrafo del artículo 44 de la Ley 105 de $1993^{[41]}$, en materia de transporte, estas se encontraban ya delimitadas en relación con las movilizaciones que se realizaran entre los municipios que la conformaban y no al interior de cada uno de ellos ${ }^{42}$.

38 Ibíd. Artículo 6.

39 La transcripción de las funciones resulta parcial, como parcial fue la lectura de las mismas por parte de quienes esta posición asumían frente a las mismas.

40 Las facultades para la planificación del transporte se disponen solo en lo que sea de su competencia y para la integración física, operacional y tarifaria de los distintos modos de transporte, en coordinación con los diferentes sistemas; además y al igual que en el caso de las facultades para la racionalización de los servicios públicos, estas se encontraban asignadas a la junta metropolitana, en unos términos muy específicos y contenidos en los literales b y e del artículo 20 de la misma ley.

41 "Parágrafo.- Las asociaciones de Municipios creadas con el fin de prestar servicio unificado de transporte, las provincias, los territorios indígenas y las áreas metropolitanas, elaborarán en coordinación con las autoridades de sus Municipios integrantes y con las de los niveles departamentales y regionales, planes de transporte que comprendan la totalidad de los territorios bajo su jurisdicción" (entiéndase transporte metropolitano).

42 La anterior no solo resulta de la regulación de los perímetros de transporte, sino igualmente de la definición del radio de acción del transporte metropolitano, contenida en los artículos $8 .^{\circ}$ del Decreto 170 de 2001 y 24 del Decreto 172 de 2001 , insertos hoy en los artículos 2.2.1.1.1.1 y 2.2.1.3.5.3 del Decreto 1079 de 2015, respectivamente, las cuales son del siguiente tenor: "Artículo 8. ${ }^{\circ}$ - Clasificación. Para los efectos previstos en este decreto la actividad transportadora del radio de acción metropolitano, distrital y municipal se clasifica [...] Según el radio de acción: a) Metropolitano. Cuando se presta entre municipios de una área metropolitana constituida por la Ley...”. "Artículo 24. Radio de acción distrital o municipal. Entiéndase por 
En este sentido, al establecerse las "relaciones entre el área metropolitana, los municipios integrantes y otras entidades", se determinó que "las Áreas Metropolitanas se ocuparán de la regulación de los hechos metropolitanos"43, entendiendo por estos "aquellos fenómenos económicos, sociales, tecnológicos, ambientales, físicos, culturales, territoriales, políticos o administrativos, que afecten o impacten simultáneamente a dos o más de los municipios que conforman el Área Metropolitana" ${ }^{44}$. Con lo que podría entenderse despejada toda duda sobre su competencia en materia de transporte terrestre, la que no poseen en estas materias cuando la actividad resuelva necesidades del servicio de orden estrictamente municipal.

No obstante, si alguna de las atribuciones básicas de las áreas metropolitanas no le permitiera a alguien aceptar los argumentos anteriores y se quisiera, a pesar de ellos, continuar afirmando que la conformación de un área metropolitana conlleva el desplazamiento de las competencias de la autoridad municipal para la organización del transporte en su territorio, dicha postura resultaría contraevidente ante el contenido del artículo 38 de la Ley 1625 de 2013, de acuerdo con el cual "En ningún caso los actos administrativos que profieran las Áreas Metropolitanas dada su condición de instancia de planeación y gestión podrán vulnerar la autonomía de los municipios que la conforman" 45 .

Por lo anterior, lo dicho en relación con la limitación general de las competencias en este documento ${ }^{46}$, resulta en todo aplicable a las áreas metropolitanas, las cuales se constituirán en autoridad competente para la organización, control y vigilancia del transporte en los servicios cuyo origen y destino se encuentren comprendidos dentro de su área y que superen a su vez la jurisdicción de uno

radio de acción distrital o municipal el que se presta dentro de la jurisdicción de un distrito o municipio. Comprende las áreas urbanas, suburbanas y rurales y los distritos territoriales indígenas de la respectiva jurisdicción.

"El radio de acción metropolitano es el que se presta entre los municipios que hacen parte de un área metropolitana". Si bien estas disposiciones son de jerarquía normativa inferior, la misma continua vigente en la medida que no la contraría y por el contrario, corresponde al ejercicio de competencias propias del Ejecutivo.

43 Congreso de la República. Ley 1625 (29 de abril de 2013). Artículo 9.

44 Ibíd. Artículo 10.

45 Ibíd. Artículo 38.

46 Esto es, principalmente, la afirmación que atrás realizábamos en el sentido de que el origen y destino de la ruta como entorno del desplazamiento y a su vez de la necesidad y el fenómeno social, configura el perímetro del transporte y este, a su vez, define por un factor que considera la autonomía territorial, cuál es en materia de organización, vigilancia y control, la autoridad competente; sin que, como decíamos, pueda entenderse alguna subsumida bajo otra a la que pertenece. 
de los municipios que la conforman ${ }^{47}$, sin perjuicio de las facultades que en materia de planeación le corresponden al interior de su territorio ${ }^{48}$.

Lo propio ocurre en el sistema de servicio público urbano de transporte masivo de pasajeros, en el cual se establece como condición para su cofinanciación la constitución formal de "una autoridad única de transporte para la administración del sistema"49. Guardando coherencia con lo establecido por el legislador, el artículo 18 del Decreto 3109 de 1997 dispone que "La autoridad única de transporte ejercerá las funciones de vigilancia y control de cumplimiento de las condiciones de habilitación y operación establecidas en dicho Decreto, que refiere específicamente el transporte masivo".

Con este claro marco de competencias, dos han sido las desviaciones que se pretendió introducir con la finalidad de obtener una visión ampliada del mismo: una en relación con el factor territorial como criterio determinador de la competencia; la otra, en relación con la mutabilidad de la naturaleza de los servicios al contacto con el transporte masivo.

En lo que al factor territorial se refiere, al estar el servicio público urbano de transporte masivo de pasajeros orientado a "asegurar la prestación de un servicio eficiente que permita el crecimiento ordenado de las ciudades y el uso racional del suelo urbano" ${ }^{50}$, se le determina un área de influencia "comprendida por las áreas urbanas y suburbanas y por los municipios a los cuales el sistema sirve de interconexión directa o indirecta" ${ }^{51}$. Algunos equivocadamente entendieron que la determinación del territorio que forma parte del área de influencia resultaba en la definición -en estos territorios- de una competencia general de la autoridad de transporte masivo, con desplazamiento de la competencia de la autoridad local; verdadero despropósito, no solo porque asumir tal posición en la discusión implicaría contrariar lo dispuesto

47 Congreso de la República. Ley 336 (20 de diciembre de 1996). Artículo 8; Presidente de la República. Decreto 170 (5 de febrero de 2001). Artículo 8, y Presidente de la República. Decreto 172 (5, febrero de 2001). Artículo 24; estos dos últimos insertos hoy en los artículos 2.2.1.1.1.1 y 2.2.1.3.5.3 del Decreto 1079 de 2015.

48 Las competencias que se tienen en materia de transporte por parte de las áreas metropolitanas no dan para disponer la organización del mismo, pues además de las limitaciones de rango legal ya referidas y que delimitan claramente el alcance de sus competencias, el artículo 319 de la Constitución solo refiere la racionalización de los mismos. Concepto que si bien impacta en la organización, no la abarca en toda su integridad.

49 Congreso de la República. Ley 310 (6 de agosto de 1996). Por medio del cual se modifica la Ley 86 de 1989, Diario Oficial, n. ${ }^{\circ} 42853$. Artículo 2, numeral 5.

50 Congreso de la República. Ley 86 (29 de diciembre de 1989). Por la cual se dictan normas sobre sistemas de servicio público urbano de transporte. Artículo 1. En: http: //www. alcaldiabogota.gov.co/sisjur/normas/Norma1.jsp?i=3426no. 48776.

51 Ibíd. 
en los artículos 1.․, 287 y 288 de la Constitución Política, sino por cuanto la competencia de la autoridad de transporte masivo, como atrás establecimos, se circunscribe específicamente a los sistemas de servicio público urbano de transporte masivo de pasajeros y estos no están conceptualmente diseñados ni destinados a atender la totalidad de la demanda de transporte al interior de los municipios que integran dicha área de influencia ${ }^{52}$.

Para este caso particular, esta afirmación cuenta con declaraciones manifiestas del legislador, quien en el parágrafo 3 del artículo 134 de la Ley 1450 de 2011, modificado por el artículo 34 de la Ley 1753 de 2015, define el subsistema de transporte complementario como "el sistema de transporte público colectivo que atiende la demanda de transporte colectivo que no cubre el sistema de transporte masivo o estratégico" $" 53$.

Concuerda esta posición frente al alcance de las competencias de la autoridad de transporte masivo con la fijada por la Sección Primera del Consejo de Estado, que anuló disposiciones adoptadas por la Secretaría de Tránsito y Transporte de Santa Fé de Bogotá D.C., en ejercicio de sus competencias como autoridad única de transporte ${ }^{54}$, en las cuales reestructuraba rutas nacionales con origen en el Distrito Capital y destino en el municipio de Soacha, así como rutas colectivas urbanas del municipio de Soacha; pues aun siendo ambos parte del área de influencia, las primeras resultaban de competencia del Ministerio de Transporte y las segundas de la Alcaldía del municipio vecino. En esa oportunidad la corporación se pronunció en los siguientes términos:

Debe la Sala examinar si la entidad demandada al expedir la Resolución 1357 de 2000, usurpó competencias del Ministro del Transporte y del Alcalde de Soacha porque, según la actora, ésta incluyó la adjudicación de rutas en el trayecto Bogotá-Soacha-Bogotá y dentro del municipio de Soacha.

Sobre el particular se tiene que en efecto los artículos 12,13 y 14 del acto acusado se refieren a rutas que hacen recorridos en Bogotá que también hacen recorridos intermunicipales con destino al municipio de Soacha y dentro de éste; la entidad demandada alega que estas rutas con destino al municipio de Soacha ya estaban

52 De conformidad con el artículo 3..$^{\circ}$ del Decreto 3109 de 1997, el Sistema Integrado de Transporte Masivo - SITM es un "sistema que cubre un alto volumen de pasajeros y da respuesta a un porcentaje significativo de necesidades de movilización".

53 Congreso de la República. Ley 1450 (16 de junio de 2011). Por la cual se expide el Plan Nacional de Desarrollo, 2010-2014, Diario Oficial, n. ${ }^{\circ}$ 48102. Artículo 134, parágrafo 3.

54 Ministerio de Transporte. Resolución 266 (16 de febrero de 1999). Por la cual se aprueba la Autoridad Única de Transporte para la administración del Sistema de Servicio Público Urbano de Transporte Masivo de Pasajeros para Santa Fé de Bogotá. En: http://www.alcaldiabogota.gov. co/sisjur/normas/Norma1.jsp?i=29060. 
aprobadas por el Ministerio del Transporte mediante Resolución 1549 del 6 de septiembre de 1985 expedida por el entonces denominado INTRA (folio 369) y que las rutas dentro del municipio de Soacha, están autorizadas por este municipio mediante las Resoluciones 015 de 1989 y 798 de 1999 (folios 242 a 248) en virtud de las atribuciones que le otorga la Ley 336 de 1996 y que por lo anterior, la Secretaría de Tránsito y Transporte enmendó su error mediante Resolución 156 del 23 de mayo de 2002 que modificó el acto acusado.

Del contenido de la disposición demandada se colige que la autoridad de Transporte de Bogotá, como ella lo reconoció, asumió competencias que no le corresponden, por lo cual la Sala declarará nulas estas disposiciones en lo que hace relación al recorrido intermunicipal Bogotá-Soacha-Bogotá y a las rutas dentro del municipio de Soacha ${ }^{55}$.

Y no podría ser de otra manera, si como ya mencionábamos, según se desprende de lo consagrado en el numeral 5 del artículo 2. ${ }^{\circ}$ de la Ley 310 de 1996 y en el artículo 18 del Decreto 3109 de 1997, la autoridad única de transporte se conforma para la administración del Sistema de Servicio Público Urbano de Transporte Masivo de Pasajeros y ejerce las funciones de vigilancia y control de cumplimiento de las condiciones de habilitación y operación del transporte masivo exclusivamente.

Podemos afirmar entonces que el concepto de área de influencia no corresponde a la asignación de competencias generales para la organización del transporte dentro del territorio que la conforma y, por el contrario, se encuentra más próximo al aspecto técnico que dentro de la planeación del proyecto permite medir el impacto en la comunidad y en los demás sistemas y modalidades de transporte; en este último caso, para su correspondiente reorganización, en atención a la prioridad que corresponde al sistema masivo según dispone el artículo 3. ${ }^{\circ}$ de la Ley 336 de 1996 y a la necesaria articulación para la atención integral de la demanda.

De lo anterior se evidencia que los planteamientos expuestos para la diferenciación de las competencias de las autoridades del orden municipal y metropolitano, en relación con el entorno en el que se desenvuelve y agota la demanda de movilización y su relación con la organización política del país, aparentemente se superan en el caso de la autoridad de transporte de los sistemas de servicio público urbano de transporte masivo de pasajeros;

55 Consejo de Estado. Sala de lo Contencioso Administrativo, sección primera. Exp. Rad. n. ${ }^{\circ}$ 25000-23-24-000-2002-00480-01, noviembre 26 de 2008. C.P.: Martha Sofía Sanz Tobón. En: http://webcache.googleusercontent.com/search?q=cache:WFE_rJRGTd8J:190.24.134.67/ SENTENCIAS/SENTPROC/F25000232400020020062901 PARAADJUNTARSENTENCIA20100818095943. $\mathrm{DOC}+\& \mathrm{~cd}=1 \& \mathrm{hl}=\mathrm{es} \& \mathrm{ct}=\mathrm{clnk} \& \mathrm{gl}=\mathrm{co}$. 
autoridad a la que, independientemente de los criterios mencionados y a pesar de que el concepto de área de influencia no resulta equiparable al de jurisdicción territorial, le corresponden competencias en la materia que responden a la dimensión del sistema y su operación, y no necesariamente a la geografía política del territorio en el que se desarrolla.

Y decimos que aparentemente, por cuanto de conformidad con la lectura que del artículo 86 de la Ley 336 de 1996 ha realizado la Corte Constitucional en sentencia C- 66 de 1999, el Ministerio de Transporte es "la autoridad de transporte para la administración del sistema de transporte masivo de acuerdo con los criterios de coordinación institucional”; mientras que en el artículo 5. ${ }^{\circ}$ del Decreto 3109 de 1997 establece que la autoridad única de transporte para la administración del sistema integrado de transporte masivo será aquella "constituida para el efecto por el ente territorial o administrativo correspondiente", lo que nos aproxima nuevamente, pero de manera parcial, a un factor territorial de competencia, que en el perímetro nacional pertenece al Ministerio de Transporte. Lo expuesto mantiene validez aun en el caso de una lectura que indique que aquella autoridad de que trata el citado artículo $5 .{ }^{\circ}$ del Decreto 3109, en los términos del artículo 86 ibíd., ejerce en delegación las funciones consignadas en el precepto reglamentario.

En relación con la mutabilidad de la naturaleza de los servicios al contacto con el transporte masivo, la misma se ha sostenido en los casos en que el transporte público colectivo se integra al Sistema Metro, afirmándose que en estos eventos el primero pasa a considerarse, junto con este último, como un transporte masivo y por ende de la órbita de competencia de la autoridad de transporte masivo; se pasa por alto en estas conclusiones que la integración del transporte colectivo con el sistema metro no desnaturaliza el primero ni lo convierte en el segundo.

En este sentido, en el auto del 23 de febrero de 2015, dictado dentro del proceso de nulidad simple adelantado sobre el Acuerdo Metropolitano 006 de 2014, radicado 05001333303020140133700, la Juez Treinta Administrativa de Oralidad del Circuito de Medellín sostuvo:

En lo que respecta a los artículo 2,3 y 4 del Acuerdo que hacen referencia a la expedición de autorizaciones para el servicio de alimentación al sITVA de CONVENIOS DE COLABORACIÓN EMPRESARIAL, estima esta judicatura que si bien constituye un asunto de fondo en el asunto de la referencia y que el momento oportuno sería la sentencia, lo cierto es que se trate o no de TRANSPORTE COLECTIVO para asumir la calidad de ALIMENTADOR, éste se concibe como un complementario del sistema integral de transporte masivo, y a consideración de este Despacho no podría tener un tratamiento jurídico aislado. 
Esta posición no es novedosa o reciente, pues desde el año 2006 el Ministerio de Transporte, atendiendo una petición del entonces Director del Área Metropolitana del Valle de Aburrá elevada en relación con el alcance de las competencias de la autoridad de transporte masivo, afirmó: "Una vez reestructuradas las rutas dentro del área de influencia del SITM las autoridades de transporte de carácter local perderían la competencia, en razón a la naturaleza de las mismas, recayendo la competencia en el Área Metropolitana del Valle de Aburrá, de conformidad con las resoluciones 5256 de 2003 y 2179 de $2006^{[56]}$, respectivamente" 57 .

Esta falta de claridad se debe a que, por un lado, se confunde al sistema alimentador, que junto con el sistema estructural conforma el Sistema Integrado de Transporte Masivo, con la integración entre las diferentes modalidades de transporte, y por el otro, a que se entiende el Sistema Integrado de Transporte Masivo como el Sistema bajo el cual se agrupan los demás sistemas de transporte. Para la fundamentación de lo anterior basta con introducir una definición aproximada de cada uno de los sistemas de transporte, con algunas consideraciones que procederemos a realizar posteriormente.

- Sistema Integrado de Transporte Masivo - SITM

De conformidad con lo establecido en los artículos 1. . de la Ley 310 de 1996, 3. ${ }^{\circ}, 4^{\circ}$ y 12 del Decreto 3109 de 1997 y en el parágrafo 1 del artículo 132 de la Ley 1450 de 2011, modificado por el artículo 32 de la Ley 1753 de 2015, se entiende por SITM las soluciones de transporte público para municipios o áreas metropolitanas con población superior a los 600.000 habitantes, que como sistema cubre un alto volumen de pasajeros y da respuesta a un porcentaje significativo de necesidades de movilización, a través de una combinación organizada de infraestructura y equipos, dentro de un área de influencia comprendida por las áreas urbanas, suburbanas y por los municipios a los cuales el sistema sirve de interconexión directa o indirecta. Está compuesto por un Sistema Estructural y un Sistema Alimentador que se integrará física y operativamente, constituido por rutas de alimentación.

La integración a que se refiere la denominación de esta clase de sistemas no es otra que aquella que se exige entre el sistema estructural y el sistema alimentador, lo que se corrobora con el contenido del concepto de Sistema Integrado de Transporte Público.

56 Mediante estas resoluciones se designan autoridades de transporte masivo en sistemas de transporte específicos.

57 Ministerio de Transporte. MT-1350-2-49394 (4 de octubre de 2006). En: file:///C:/ Users/usuario/Downloads/Concepto_0658.pdf 
- Sistemas Estratégicos de Transporte Público - SETP

Al tenor de lo dispuesto por el artículo 2. ${ }^{\circ}$ del Decreto 3422 de 2009 y en el parágrafo 1 del artículo 132 de la Ley 1450 de 2011, modificado por el artículo 32 de la Ley 1753 de 2015, se entiende por SETP las soluciones de transporte público para municipios o áreas metropolitanas con población entre los 250.000 y los 600.000 habitantes, adoptadas a través de "servicios de transporte colectivo integrados y accesibles para la población EN RADIO DE ACCIÓN, que deberán ser prestados por empresas administradoras integrales de los equipos, con sistemas de recaudo centralizado y equipos apropiados, cuya operación será planeada, gestionada y controlada mediante el Sistema de Gestión y Control de Flota, SGCF".

- Subsistema de Transporte Complementario - STC

De conformidad con lo establecido en el parágrafo 3 del artículo 134 de la Ley 1450 de 2011, modificado por el artículo 34 de la Ley 1753 de 2015, se entiende como Subsistema de Transporte Complementario el sistema de transporte público colectivo (STC) que atiende la demanda de transporte colectivo que no cubren el Sistema de Transporte Masivo (SITM) ni el Estratégico (SEPT).

- Sistema Integrado de Transporte Público - SITP

De acuerdo a lo establecido en las Bases del Plan Nacional de Desarrollo 2010-2014 y 2014-2018 y en el parágrafo 1 del artículo 132 de la Ley 1450 de 2011, modificado por el artículo 32 de la Ley 1753 de 2015, se entiende por SITP al conjunto de soluciones que a través de la integración de los diferentes sistemas -entiéndase STC y SITM- busca atender la demanda total en sus áreas urbanas, proporcionando cobertura al 100\% de las necesidades de transporte colectivo.

Como anticipábamos, es dentro del Sistema Integrado de Transporte Público que se reclama la integración entre los diferentes sistemas de transporte urbano.

- Sistemas Integrados de Transporte Regional - SITR

Atendiendo lo establecido en el parágrafo 1 del artículo 132 de la Ley 1450 de 2011, modificado por el artículo 32 de la Ley 1753 de 2015, y lo dispuesto en las Bases del Plan Nacional de Desarrollo 2014-2018, los SITR son sistemas diseñados para permitir la integración de las soluciones de movilidad de la ciudad con la región en que esta se inserta, definiendo los mecanismos que faciliten la integración operacional y tarifaria de los SITR con los sistemas de 
transporte urbano e interurbano, en pos de aumentar de esta manera la cobertura de los SITM y los SETP ${ }^{58}$.

Con los anteriores conceptos queda entonces conformado un mapa de los sistemas de transporte público que se representa con la siguiente gráfica.

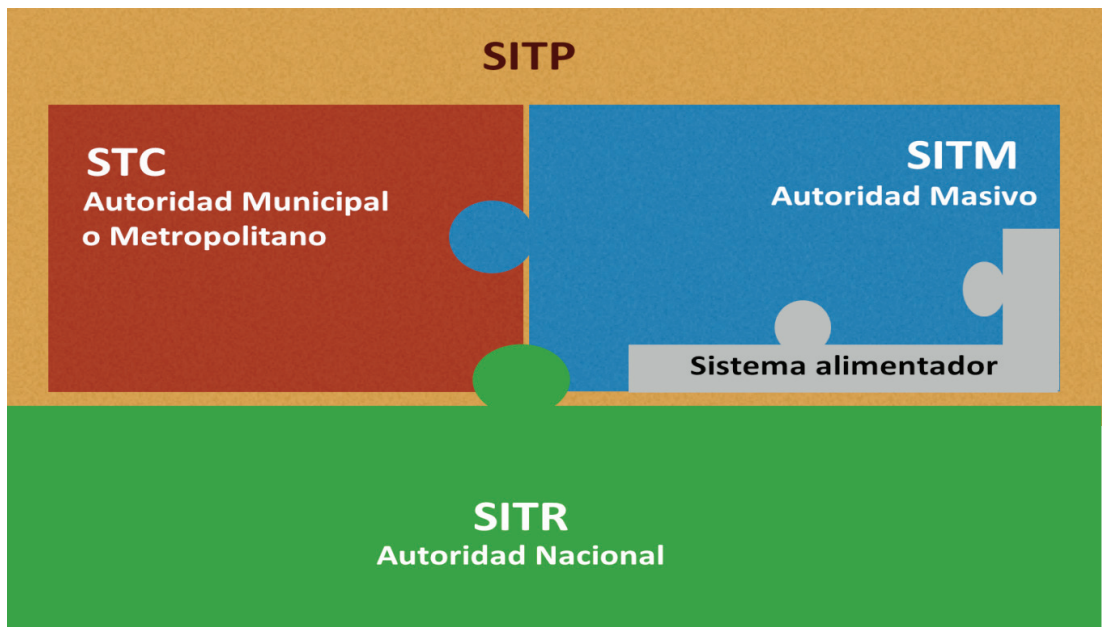

Pretender entonces que la integración de una ruta de transporte colectivo urbano con el sistema de transporte masivo implica considerar en adelante la misma como una ruta alimentadora que conforma el sistema de alimentación a que nos hemos referido, o que por el hecho de la integración entre los sistemas o servicios de transporte todos ellos adquieren la naturaleza de un Sistema Integrado de Transporte Masivo, implicaría negar la existencia de las demás modalidades y sistemas de transporte y considerar el Sistema Integrado de Transporte Masivo el único sistema, absorbiendo todos los demás, pues finalmente cada uno de ellos está diseñado para interconectarse e integrarse, en lo que ha dado en denominarse SITP y SITR.

Corolario de lo anterior, así como no se subsume el municipio en el área metropolitana o esta en el departamento, del mismo modo no se subsume el transporte colectivo en el masivo por el hecho de su integración con este, y preserva cada autoridad sus competencias. Como anticipábamos, considerar

58 No introduciremos el concepto de Sistema Nacional de Transporte como uno más de los anteriores, pues a pesar de que compartimos la visión que del mismo se tuvo en el salvamento de voto de la sentencia C-066 de 1999, la falta de proximidad de su operatividad no lo hace pertinente en esta ocasión, lo que se corrobora con su alcance nacional y no regional, siendo este último el alcance que nos convoca. 
lo contrario solo puede ser consecuencia de un inexcusable error, producto de confundir el sistema alimentador con el acceso de los usuarios al servicio masivo a través de la integración que se realice entre este y otra modalidad o sistema de transporte.

Para refutar parcialmente lo dicho no podrá afirmarse que el Subsistema de Transporte Complementario, como el Sistema Integrado de Transporte Público, es un concepto vacío a causa de su falta de reglamentación, como no lo han sido los Sistemas de Gestión y Control de Flota o los Sistemas de Recaudo, actualmente implementados; por lo que su desarrollo entre tanto corresponderá realizarlo a la autoridad de transporte local, en ejercicio de su competencia para la organización del transporte y dentro de todo un abanico de posibilidades propias de este tipo de soluciones. Así lo reconocen las Bases del Plan Nacional de Desarrollo 2014-2018, cuando al pronunciarse sobre las formas de apoyar la gestión y financiación de los sistemas se refieren literalmente a "los SITM, SETP, SITP, SITR o cualquier sistema de transporte público urbano", el que en este último caso podrá operar dentro de los parámetros del Servicio Público de Transporte Terrestre Automotor Colectivo Metropolitano, Distrital y Municipal de Pasajeros.

Y es que, recuérdese, el Servicio Público de Transporte Terrestre Automotor Colectivo Metropolitano, Distrital y Municipal de Pasajeros, según se desprende de lo dispuesto en los artículos 7., 26 y 27 del Decreto 170 de $2001^{[59]}$, puede ser autorizado o restructurado para operar como un Sistema de Transporte.

La posición sostenida en relación con la no mutabilidad de la naturaleza del servicio por su integración con otros, encontró recientemente sustento legal tácito en lo dispuesto en el parágrafo 7 del artículo 132 de la Ley 1450 de 2011 -modificado por el artículo 32 de la Ley 1753 de 2015-, según el cual,

Con el propósito de integrar operacionalmente los SITM, los SITP y los SETP con el transporte complementario de las ciudades y/o el transporte intermunicipal de pasajeros de corta distancia, las autoridades territoriales, conjuntamente con

59 "Artículo 7. - Definiciones. Para la interpretación y aplicación del presente decreto, se tendrán en cuenta las siguientes definiciones: [...] Sistema de rutas. Es el conjunto de rutas necesarias para satisfacer la demanda de transporte de un área geográfica determinada...". “Artículo 26.- Licitación pública. La autorización para la prestación del servicio público de transporte colectivo de pasajeros del radio de acción metropolitano, distrital y municipal en una ruta o sistema de rutas será el resultado de una licitación pública, en la que se garantice la libre concurrencia y la iniciativa privada para la creación de nuevas empresas...". "Artículo 27.- Determinación de las necesidades de movilización. La autoridad metropolitana, distrital o municipal competente será la encargada de determinar las medidas conducentes a satisfacer las necesidades insatisfechas de movilización". Decreto 170 (5 de febrero de 2001). Artículos 2.2.1.1, 2.2.1.1.5.4 y 2.2.1.1.5.5 del Decreto 1079 de 2015, respectivamente. 
el Ministerio de Transporte según sea el caso, podrán promover mecanismos de organización entre los mismos, a través de instrumentos como los acuerdos comerciales o convenios de colaboración entre empresas que estén debidamente habilitadas.

Visto un panorama general de las autoridades competentes para la organización de la actividad transportadora, procederemos a complementar el mismo con otras autoridades cuyas facultades impactan en el ejercicio de aquellas que a las anteriores corresponden.

\section{A. Otras autoridades y competencias relevantes en materia de transporte}

Como quedó expuesto en la sentencia de la Sección Tercera del Consejo de Estado, C.P.: Jaime Orlando Santofimio Gamboa, rad. 73001-23-31-000-200002654-01(30026) del 12 de agosto de 2014 -reseñada en el boletín jurídico del Centro de Estudios de Derecho del Transporte de la Universidad Externado de Colombia-, la garantía a la libre locomoción consagrada en el artículo 24 de la Constitución "no se cumple cuando pese a que a las personas formalmente no se les impide su libre circulación, se les obliga a transitar por vías públicas que esconden verdaderas emboscadas para sus transeúntes"; lo que resulta igualmente en una violación del derecho urbanístico. En concordancia con lo anterior, en la parte resolutiva de la sentencia se ordenó al municipio, dentro de las medidas de reparación, "que se prohíba los paraderos de la rutas de transporte público urbano, en la zona adyacente al canal en los puntos en que éste se encuentra a nivel de la avenida El Jordán”, en atención al riesgo a que se ven expuestos los usuarios.

Así encontramos, como ejercicio antecedente, coetáneo y permanente respecto de la organización del servicio público de transporte, la debida planeación y la regulación necesaria de la actividad, abordada desde un concepto de movilidad integral que involucra disposiciones de orden urbanístico, sin agotarse simplemente en la autorización de servicios o recorridos.

En estos aspectos, específicamente en el contexto urbano que venimos tratando, podemos empezar por mencionar el mandato contenido en el artículo 44 de la Ley 105 de 1993 de conformidad con el cual "Los planes de transporte e infraestructura de los distritos y municipios harán parte de sus planes de desarrollo"; debiendo contener una parte estratégica y un plan de inversiones y "corresponder a las necesidades y prioridades del transporte y a su infraestructura en la respectiva Entidad Territorial" ${ }^{60}$.

60 Congreso de la República. Ley 105 (30 de diciembrede 1993). Artículo 44. 
Según se establece el artículo 33 de la Ley 152 de 1994, en las entidades territoriales del nivel municipal o distrital son autoridades de planeación: el Alcalde, máximo orientador de la planeación en la respectiva entidad territorial; la Secretaría, Departamento Administrativo u Oficina de Planeación, a quien, entre otras funciones, le corresponde desarrollar las orientaciones de planeación impartidas por el Alcalde o Gobernador; y las demás Secretarías, Departamentos Administrativos u Oficinas especializadas en su respectivo ámbito funcional, para nuestro objeto de estudio las de Tránsito y Transporte, que ejercerán sus funciones de acuerdo con las orientaciones de las autoridades precedentes.

En materia de ordenamiento territorial encontramos que "El ordenamiento del territorio constituye en su conjunto una función pública, para el cumplimiento de, [entre otros fines, el de] posibilitar a los habitantes el acceso a las [...] infraestructuras de transporte" ${ }^{61}$. Esta función se desarrolla mediante la acción urbanística -entendida como la "referida a las decisiones administrativas y a las actuaciones urbanísticas [...], relacionadas con el ordenamiento del territorio y la intervención en los usos del suelo" ${ }^{62}$, entre ellas , las de "Localizar y señalar las características de la infraestructura para el transporte [...] [y las de] Dirigir y realizar la ejecución de obras de infraestructura para el transporte" ${ }^{63}$.

Para el desarrollo de estos fines se incluye dentro de los tres componentes del plan de ordenamiento territorial ${ }^{64}$-considerado por el legislador como instrumento básico para desarrollar el proceso de ordenamiento del territorio municipal ${ }^{65}$ - un componente urbano, tenido a su vez como "instrumento para la administración del desarrollo y la ocupación del espacio físico clasificado como suelo urbano y suelo de expansión urbana, que integra políticas de mediano y corto plazo, procedimientos e instrumentos de gestión y normas urbanísticas [...] [el cual deberá como mínimo contener]: [...] La localización y dimensionamiento de la infraestructura para el sistema vial, [y] de transporte" $" 66$.

Estos documentos de planeación no pueden considerarse accesorios en el ejercicio de las competencias en la materia que nos ocupa, pues entre lo dis-

61 Congreso de la República. Ley 388 (18 de julio 1997). Por la cual se modifica la Ley 9 de 1989, y la Ley 2 de 1991 y se dictan otras disposiciones, Diario Oficial, n. ${ }^{\circ} 43091$. Artículo 3.

62 Ibíd. Artículo 8.

63 Ibíd.

64 Ibíd. Artículo 11.

65 Ibíd. Artículo 9.

66 Ibíd. Artículo 13. 
puesto en los planes de ordenamiento, los programas de ejecución definirán con carácter obligatorio las actuaciones sobre el territorio que, encontrándose previstas en aquel, serán ejecutadas durante el período de la correspondiente administración municipal y definirán los programas y proyectos de infraestructura de transporte que se ejecutarán en el mismo periodo ${ }^{67}$.

Por último, en materia de autoridades directamente relacionadas con la planeación, organización y ejecución del transporte en el orden territorial, ha de mencionarse la competencia otorgada por el parágrafo primero del artículo 105 de la Ley 769 de 2002 a las autoridades de tránsito, según el cual estas "deberán consultar con las comunidades el uso de las vías cuando no se trate de vías arterias o autopistas, principales y secundarias, para la definición de las rutas de transporte público. Si las juntas administradoras votan negativamente un tramo de una ruta, ésta no se podrá autorizar". Asimismo, el parágrafo 2 establece que "En todo caso, las vías principales y secundarias que se autoricen para rutas de transporte público requieren concepto técnico de la autoridad competente de que son aptas para resistir el tránsito de rutas de transporte público".

Vemos de lo expuesto cómo estas competencias para la planeación del transporte y la infraestructura mantienen lógicamente aquella conexión con la autonomía propia de las diferentes entidades territoriales, evidenciada igualmente en las competencias para la organización de la actividad transportadora, competencias que en el contexto de una conurbación y dada las necesidades que dentro de la misma surgen para sus habitantes, consideramos deben verse matizadas de una manera importante. Por lo que ahora abordaremos la viabilidad de su ejercicio en dirección a las soluciones regionales integradas de transporte.

\section{LA ORGANIZACIÓN DEL TRANSPORTE EN EL ENTORNO REGIONAL}

Tal como lo afirma la Corte Constitucional en sentencia C-615 de 2002 $2^{[68]}$, dadas las necesidades que a través del servicio público de transporte se procura satisfacer, este encarna "una actividad económica que compromete la satisfacción de las necesidades básicas de la población, y por ello mismo la eficacia de ciertos derechos fundamentales, [por lo que] [...] su prestación se somete a especial regulación y control".

Pero analizados los perímetros del transporte y su incidencia en la configuración de la autoridad de transporte competente, y expuesto el interés

67 Ibíd. Artículo 18.

68 Corte Constitucional. Sentencia C-615; Exp.D-3881, 8 de agosto de 2002. M.P.: Marco Gerardo Monroy Cabra. En: http://www.alcaldiabogota.gov.co/sisjur/normas/Norma1.jsp?i=630. 
nacional que concurre en la actividad -el que armoniza con la voluntad del constituyente de conceder la regulación de los servicios públicos al legislativo-, veamos el papel que deben cumplir las diferentes autoridades para la solución de transporte público en aquellos servicios que, desbordando la jurisdicción municipal o metropolitana, inciden no obstante en ella.

\section{A. Condiciones para el ejercicio de las competencias en materia de transporte}

Una primera respuesta a esta necesidad de articulación de servicios que corresponde organizar simultáneamente a diferentes autoridades de transporte la encontramos en las condiciones que para el ejercicio de las competencias impone la Carta Política. De conformidad con esta, "Las competencias atribuidas a los distintos niveles territoriales serán ejercidas conforme a los principios de coordinación, concurrencia y subsidiariedad".

De conformidad con los anteriores principios, y en consonancia con lo dispuesto en el artículo $4 .^{\circ}$ de la Ley 136 de 1994, modificado por el artículo $3 .^{\circ}$ de la Ley 1551 de 2012, en razón de que las competencias de las entidades del nivel territorial y nacional, lejos de ser excluyente resultan dependientes entre sí para alcanzar los fines del Estado, al momento de ejercer dichas competencias las diferentes autoridades están llamadas a armonizar sus actuaciones con todas aquellas en que la misma tenga incidencia. Condición que se impone igualmente y de manera expresa en el Estatuto del Transporte cuando afirma que las autoridades de transporte "ejercerán sus funciones con base en los criterios de colaboración y armonía propios de su pertenencia al orden estatal" ${ }^{69}$. Ahora, en el tema que nos ocupa, esta pertenencia al orden estatal que recuerda la norma no es otra cosa que la manifestación del principio unitario que condiciona el ejercicio de las facultades propias de las entidades territoriales, y que como límite se impone sobre la autonomía territorial que les es propia.

Esta, que entendemos como limitación, ha recibido el aval constitucional en una de sus más caras manifestaciones, la que se deprende directamente del Sistema Nacional de Transporte, el que a su vez representa esa visión totalizadora del servicio que abre las puertas a las respuestas regionales. Dicho Sistema, que de acuerdo con lo dispuesto en el inciso $2 .^{\circ}$ del artículo $1 .^{\circ}$ de la Ley 105 de 1993 está conformado en general por las "dependencias de los sectores central o descentralizado de cualquier orden, que tengan funciones relacionadas con esta actividad", permitió a la Corte Constitucional encontrar razonabilidad en las facultades que el artículo 60 de la Ley 336 de 1996 
otorga al Ministerio de Transporte para la revocatoria oficiosa de los actos administrativos de carácter particular y concreto, dictados por las autoridades locales de transporte terrestre automotor.

Estas facultades, junto con el control de tutela otorgado al Ministerio de Transporte sobre el ejercicio de las competencias en la materia por las demás autoridades ${ }^{70}$, resaltan no solo la preponderancia del interés nacional en la actividad, sino que adicionalmente fortalecen el concepto de Sistema Nacional de Transporte, que en palabras del magistrado Eduardo Cifuentes Muñoz apunta a "la integración del territorio [...] [a través de] la articulación de los distintos modos de transporte" 71 .

Así, las competencias concurrentes para la organización del transporte deben coordinarse al interior del Sistema de Nacional de Transporte, lo que en opinión de la Corte Constitucional "impone que su ejercicio se haga de manera armónica, de modo que la acción de los distintos órganos resulte complementaria y conducente al logro de los fines de la acción estatal. Esa coordinación debe darse desde el momento mismo de la asignación de competencias y tiene su manifestación más clara en la fase de ejecución de las mismas" 72 , sin olvidar que, según lo afirmó la corporación, la "Coordinación implica participación eficaz en la toma de decisiones" ${ }^{73}$.

Esta necesidad se enfatiza en materia de planeación cuando se establece que en la elaboración de los planes de desarrollo las autoridades mencionadas anteriormente "deberán tener en cuenta [...] las políticas y estrategias del Plan Nacional de desarrollo para garantizar la coherencia" ${ }^{4}$, y que "Los planes de las entidades territoriales de los diversos niveles, ente sí y con respecto al Plan Nacional, tendrán en cuenta las políticas, estrategias y programas que son de interés mutuo y le dan coherencia a las acciones gubernamentales" 75 , documentos que, como vimos, inciden de manera directa en la organización del servicio.

70 Ley 336 (20 de diciembre de 1996). Artículo 8.

71 Salvamento de voto a la sentencia C-066 de 1999. Podemos compartir esta afirmación, entre otras múltiples razones, por interpretación gramatical del concepto y dado que aceptar la misma no nos compromete en sus alcances específicos.

72 Corte Constitucional. Sentencia C-149; Expedientes D-7828 y D-7843, 4 de marzo de 2010. M.P.: Jorge Iván Palacio Palacio. En: http://www.corteconstitucional.gov.co/ RELATORIA/2010/C-149-10.htm.

73 Corte Constitucional. Sentencia C-517; Exp. D-001, 15 de septiembre de 1992. M.P.: Ciro Angarita Barón. En: http://www.corteconstitucional.gov.co/relatoria/1992/c-517-92.htm.

74 Congreso de la República. Ley 152 (15 de julio de 1994). Por la cual se establece la Ley Orgánica del Plan de Desarrollo, Diario Oficial, n. ${ }^{\circ}$ 41450. En: http://www.alcaldiabogota. gov.co/sisjur/normas/Norma1.jsp?i=327 Artículo 32.

75 Ibíd. Artículo 45. Resaltado propio. 
Encontramos entonces, en esa coordinación y armonía con que deben ejercerse las competencias al interior del Sistema Nacional de Transporte y en el control parcial que sobre las mismas se otorga a la Autoridad Nacional por el artículo 60 de la Ley 336 de 1996, un primer instrumento general para la materialización de respuestas regionales eficientes. Procedemos a continuación con instrumentos más puntuales.

\section{B. Instrumentos para soluciones regionales de transporte}

El primero de estos lo encontramos consagrado en el artículo 319 de la Carta Política, el cual contempla la posibilidad de que los municipios constituyan una entidad administrativa a través de la conformación de un área metropolitana, cuyas competencias para la organización del transporte ya hemos abordado en el numeral II de este documento. A esta posibilidad se suman los esquemas asociativos regionales, que deberán se promovidos por el Estado para la "conformación de alianzas estratégicas que impulsen el desarrollo autónomo y autosostenible de las comunidades" 76 , los cuales, entre municipios, contemplan la posibilidad de asociación administrativa y política de los mismos "para organizar conjuntamente la prestación de servicios públicos, la ejecución de obras de ámbito regional y el cumplimiento de funciones administrativas propias, mediante convenio o contrato-plan suscrito por los alcaldes respectivos [...] en un marco de acción que integre sus respectivos planes de desarrollo en un modelo de planificación integral conjunto".

Estos instrumentos se enriquecen con la posibilidad de delegación de funciones que, desprendidas del artículo 211 de la Constitución, se establecen en la Ley 489 de 1998, y en atención a la cual las entidades del orden nacional podrán transferir el ejercicio de algunas de sus funciones a entidades del nivel territorial, y estas últimas transferir a otras autoridades aquellas funciones que les son propias $^{77}$, con las restricciones que establece la ley.

De esta manera podemos afirmar que ninguna novedad entraña el artículo 183 de la Ley 1753 de 2015, pues similares resultados era viable procurar a través de los instrumentos acabados de mencionar. Por lo que ellos, al igual

76 Ley 1454 (28 de junio de 2011). Por la cual se dictan normas orgánicas sobre ordenamiento territorial y se modifican otras disposiciones, Diario Oficial, n. ${ }^{\circ} 48115$. En: http://www. alcaldiabogota.gov.co/sisjur/normas/Norma1.jsp?i=43210 Artículo 9.

77 Ley 489 (29 de diciembre de 1998). Por la cual se dictan normas sobre la organización y funcionamiento de las entidades del orden nacional, se expiden las disposiciones, principios y reglas generales para el ejercicio de las atribuciones previstas en los numerales 15 y 16 del artículo 189 de la Constitución Política y se dictan otras disposiciones, Diario Oficial, n. ${ }^{\circ} 43464$. En: http://www.alcaldiabogota.gov.co/sisjur/normas/Norma1.jsp?i=186 Artículos 2, parágrafo, 9,11 y 14 . 
que el contenido en la normatividad introducida, son herramientas que dependen del consenso entre todas y cada una de las autoridades involucradas, lo que tradicionalmente no ha sido sencillo debido a tensiones que no nos corresponde abordar en este momento.

Pero en lo que a instrumentos puntuales se refiere, ninguno tanto como el contenido en el artículo 57 de la Ley 336 de 1996, de conformidad con el cual, cuando el servicio terrestre automotor se preste en áreas metropolitanas o ciudades vecinas con alto grado de influencia recíproca, las facultades que sobre la utilización de la infraestructura de transporte ${ }^{78}$ corresponden a cada autoridad se ejercerán en coordinación con el Ministerio de Transporte y, en una clara manifestación del principio de subsidiariedad, se determina que si la naturaleza o complejidad del asunto lo justifica, el Ministerio de Transporte asumirá conocimiento del asunto "para garantizar los derechos del usuario al servicio público".

\section{AUTORIDAD REGIONAL DE TRANSPORTE. ALGUNAS REFLEXIONES}

Como ya lo afirmamos, en un esquema asociativo entre los municipios pertenecientes a la región, impulsado incluso por el Estado, y la delegación parcial de las competencias que para la organización del transporte corresponde al Ministerio de Transporte en los servicios intermunicipales, tendríamos conformada una autoridad regional de transporte; como fue el caso del Consorcio Transportes Madrid, el cual ejerce hoy día como autoridad regional de transporte conformado mediante convenios entre entidades y delegación de competencias, logrando efectos en el servicio que justifican su emulación.

Es claro entonces que la voluntad política tiene una incidencia directa en la conformación de una autoridad regional, independientemente de su forma, por lo que la iniciativa legislativa solo será fructífera en la medida que resulte en un catalizador que permita la convergencia de la voluntad de las diferentes autoridades involucradas.

Finalmente, sin pretender adentrarnos en el alcance de las facultades de regulación de la actividad, ese interés nacional que demanda una regulación uniforme, según hemos visto, exige igualmente la determinación de las

78 "La infraestructura del transporte es un sistema de movilidad integrado por un conjunto de bienes tangibles, intangibles y aquellos que se encuentren relacionados con este, el cual está bajo la vigilancia y control del Estado, y se organiza de manera estable para permitir el traslado de las personas, los bienes y los servicios, el acceso y la integración de las diferentes zonas del país”. Ley 1682 (22 de noviembre de 2013). Por la cual se adoptan medidas y disposiciones para los proyectos de infraestructura de transporte y se conceden facultades extraordinarias, Diario Oficial, n. ${ }^{\circ}$ 48982. En: https://www.dimar.mil.co/sites/default/files/ley16822013.pdf Artículo 2. 
condiciones para su articulación con el interés local, lo que en materia de organización del transporte no es otra cosa que las condiciones para la integración y articulación de los servicios. Sin embargo encontramos pendiente de cumplimiento, entre otras, la obligación del Ministerio de Transporte de "Establecer las disposiciones que propendan por la integración [...] de los servicios de transporte"79 y la del Gobierno Nacional, establecida en el artículo 84 de la Ley 1450 de 2011, de adoptar los reglamentos técnicos y los estándares y protocolos de tecnología y establecer el uso de la tecnología en los proyectos de Sistemas Inteligentes de Tránsito y Transporte - SIT ${ }^{80}$ y los sistemas de compensación entre operadores; definiciones que resultan indispensables si se quiere una integración regional y nacional en un verdadero Sistema Nacional de Transporte ${ }^{81}$.

Quedará por analizar la constitucionalidad de la norma, la que de cara a la consagración de la facultad que para su creación se otorga al Gobierno Nacional podrá verse por algunos como violatoria de la autonomía territorial, aprovechando los argumentos expuestos por la Corte Constitucional en la sentencia C-072 de 2014, en relación con el concepto previo rendido por las Comisiones Especiales de Seguimiento al Proceso de Descentralización y Ordenamiento Territorial del Senado de la República y la Cámara de Representantes, el que se consideró no vinculante. Por otros, no obstante, podrá afirmarse la prevalencia del interés nacional y no meramente local, y las competencias que para el transporte intermunicipal corresponden al Ministerio de Transporte, pero eso ya es cuestión de otro documento.

79 Decreto 087 (17 de enero de 2011). Por el cual se modifica la estructura del Ministerio de Transporte, y se determinan las funciones de sus dependencias. Artículo 2, numeral 2.6; artículo 6, numeral 6.5 y 6.10; artículo 9, numeral 9.2.

80 Según se dispone por el parágrafo 2 del artículo 84 de la Ley 1450 de 2011, son Sistemas Inteligentes de Tránsito y Transporte, entre otros, los sistemas de gestión y control de flota y los sistemas de recaudo. La falta de reglamentación de estos últimos ya mostró sus negativas consecuencias en las condiciones de acceso y la calidad del servicio al usuario en la ciudad de Bogotá. Ley 1450 (16 de junio de 2011). Por la cual se expide el Plan Nacional de Desarrollo, 2010-2014, Diario Oficial, n. ${ }^{\circ}$ 48102. En: http://www.alcaldiabogota.gov.co/sisjur/normas/Norma1.jsp?i=43101

81 El Viceministerio de Transporte comparte el carácter indispensable cuando mediante Circular Radicado MT 20134000003711 del 9 de enero de 2013 solicita "a los señores alcaldes y a los gerentes de las Empresa de Transporte Masivo y Transporte Estratégico de las ciudades donde se desarrollan estos proyectos, abstenerse de suscribir convenios de cooperación comercial y de integración, hasta tanto el Ministerio de Transporte defina el marco regulatorio para dicha integración fiscal, operacional y tarifaria". Circular que ante las necesidades apremiantes de los usuarios, naturalmente no ha sido observada. 


\section{BIBLIOGRAFÍA}

Constitución Política de Colombia. 1991.

Ley 86 (29 de diciembre de 1989). Por la cual se dictan normas sobre sistemas de servicio público urbano de transporte. Bogotá, D.C., 1989. Artículo 1. En: http: //www.alcaldiabogota.gov.co/sisjur/normas/Norma1.jsp?i=3426 n. 48776.

Ley 105 (30 de diciembre de 1993). Por la cual se dictan disposiciones básicas sobre el transporte, se redistribuyen competencias y recursos entre la Nación y las Entidades Territoriales, se reglamenta la planeación en el sector transporte y se dictan otras disposiciones, Diario Oficial, n. ${ }^{\circ}$ 42948. En: http://www.alcaldiabogota.gov.co/sisjur/normas/Norma1.jsp?i=296

Ley 152 (15 de julio de 1994). Por la cual se establece la Ley Orgánica del Plan de Desarrollo, Diario Oficial, n.o 41450. En: http://www.alcaldiabogota.gov.co/sisjur/normas/Norma1. jsp?i=327

Ley 310 (6 de agosto de 1996). Por medio del cual se modifica la Ley 86 de 1989, Diario Oficial, n. ${ }^{\circ} 42853$.

Ley 336 (20 de diciembre de 1996). Por la cual se adopta el Estatuto Nacional de Transporte, Diario Oficial, n. ${ }^{\circ} 42948$.

Ley 388 (18 de julio de 1997). Por la cual se modifica la Ley 9 de 1989, y la Ley 2 de 1991 y se dictan otras disposiciones, Diario Oficial, n. 43091.

Ley 489 (29 de diciembre de 1998). Por la cual se dictan normas sobre la organización y funcionamiento de las entidades del orden nacional, se expiden las disposiciones, principios y reglas generales para el ejercicio de las atribuciones previstas en los numerales 15 y 16 del artículo 189 de la Constitución Política y se dictan otras disposiciones, Diario Oficial, n. ${ }^{\circ}$ 43464. En: http://www.alcaldiabogota.gov.co/sisjur/normas/Norma1.jsp?i=186

Ley 1450 (16 de junio de 2011). Por la cual se expide el Plan Nacional de Desarrollo, 20102014, Diario Oficial, n. ${ }^{\text {. }}$ 48102. En: http://www.alcaldiabogota.gov.co/sisjur/normas/ Norma1.jsp?i=43101

Ley 1454 (28 de junio de 2011). Por la cual se dictan normas orgánicas sobre ordenamiento territorial y se modifican otras disposiciones, Diario Oficial, n. ${ }^{\circ} 48115$. En: http://www. alcaldiabogota.gov.co/sisjur/normas/Norma1.jsp?i=43210

Ley 1625 (29 de abril de 2013). Por la cual se deroga la Ley Orgánica 128 de 1994 y se expide el Régimen para las Áreas Metropolitanas. Diario Oficial, Diario Oficial, n. ${ }^{\circ} 48776$.

Ley 1682 (22 de noviembre de 2013). Por la cual se adoptan medidas y disposiciones para los proyectos de infraestructura de transporte y se conceden facultades extraordinarias, Diario Oficial, n. ${ }^{\circ}$ 48982. En: https://www.dimar.mil.co/sites/default/files/ley16822013.pdf

Ley 1753 (9 de junio de 2015). Por la cual se expide el Plan Nacional de Desarrollo 2014-2018 “Todos por un nuevo país". Diario Oficial, Diario Oficial, n. ${ }^{\circ} 49.538$.

Consejo de Estado. Sala de lo Contencioso Administrativo, sección primera. Exp. Rad. n. ${ }^{\circ}$ 25000-23-24-000-2002-00480-01, 26 de noviembre de 2008. C.P.: Martha Sofía 
Sanz Tobón. En: http://webcache.googleusercontent.com/search?q=cache:WFE_rJRGTd8J:190.24.134.67/SENTENCIAS/SENTPROC/F25000232400020020062901PARAADJUNTARSENTENCIA20100818095943.DOC+\&cd=1\&hl=es\&ct=clnk\&gl=co

Corte Constitucional. Sentencia C-478; Exp. D-003, 6 de agosto de 1992. M.P.: Eduardo Cifuentes Muñoz. En: http://www.alcaldiabogota.gov.co/sisjur/normas/Norma1.jsp?i=5939 Bogotá: Corte Constitucional; Consejo Superior de la Judicatura.

Corte Constitucional. Sentencia C-517; Exp. D-001, 15 de septiembre de 1992. M.P.: Ciro Angarita Barón. En: http://www.corteconstitucional.gov.co/relatoria/1992/c-517-92.htm

Corte Constitucional. Sentencia T-604; Exp. T-4616, 14 de diciembre de 1992. M.P.: Eduardo Cifuentes Muñoz. En: http://www.corteconstitucional.gov.co/relatoria/1992/T-604-92.htm

Corte Constitucional. Sentencia C-216; Exp. D-435, 28 de abril de 1994. M.P.: Vladimiro Naranjo Mesa. En: http://www.corteconstitucional.gov.co/relatoria/1994/C-216-94.htm

Corte Constitucional. Sentencia C-535; Exp. D-1239, 16 de octubre de 1996. M.P.: Alejandro Martínez Caballero. En: http://www.corteconstitucional.gov.co/relatoria/1996/c-535-96.htm

Corte Constitucional. Sentencia C-219; Exp. D-1444, 24 de abril de 1997. M.P.: Eduardo Cifuentes Muñoz. En: http://www.alcaldiabogota.gov.co/sisjur/normas/Norma1.jsp?i=3405 Bogotá: Corte Constitucional; Consejo Superior de la Judicatura.

Corte Constitucional. Sentencia C-066; Exp. D-2117, 10 de febrero de 1999. M.P.: Fabio Morón Díaz y Alfredo Beltrán Sierra. En: http://www.corteconstitucional.gov.co/ relatoria/1999/C-066-99.htm

Corte Constitucional. Sentencia C-403; Exp. D-2324, 2 de junio de 1999. M.P.: Alfredo Beltrán Sierra. En: http://www.alcaldiabogota.gov.co/sisjur/normas/Norma1.jsp?i=5736

Corte Constitucional. Sentencia C-1187; Exp. D-2854, 13 de septiembre de 2000. M.P.: Fabio Morón Díaz. En: http://www.alcaldiabogota.gov.co/sisjur/normas/Norma1.jsp?i=14655

Corte Constitucional. Sentencia C-579; Exp.s D-3260 y D-3262, 5 de junio de 2001. M.P.: Eduardo Montealegre Lynett. En: http://www.alcaldiabogota.gov.co/sisjur/normas/Norma1.jsp?i=9622

Corte Constitucional. Sentencia T-595; Exp. T-444377, 1 de agosto de 2002. M.P.: Manuel José Cepeda Espinosa. En: http://www.corteconstitucional.gov.co/relatoria/2002/t-595-02.htm

Corte Constitucional. Sentencia C-615; Exp. D-3881, 8 de agosto de 2002. M.P.: Marco Gerardo Monroy Cabra. En: http://www.corteconstitucional.gov.co/relatoria/2002/C-615-02.htm

Corte Constitucional. Sentencia C-894; Exp. D-4552, 7 de octubre de 2003. M.P.: Rodrigo Escobar Gil. En: http://corteconstitucional.gov.co/relatoria/2003/C-894-03.htm

Corte Constitucional. Sentencia C-931; Exp. D-6265, 15 de noviembre de 2006. M.P.: Rodrigo Escobar Gil. En: http://www.corteconstitucional.gov.co/relatoria/2006/C-931-06.htm

Corte Constitucional. Sentencia C-321; Exp. OP-120, 11 de mayo de 2009. M.P.: Humberto Antonio Sierra Porto. En: http://www.corteconstitucional.gov.co/RELATORIA/2009/C-321-09.htm 
Corte Constitucional. Sentencia C-149; Exp.s D-7828 y D-7843, 4 de marzo de 2010. M.P.: jorge iván palacio palacio. En: http://www.corteconstitucional.gov.co/RELATORIA/2010/C-149-10. htm

Corte Constitucional. Sentencia C-100; Exp. D-9219, 27 de febrero de 2013. M.P.: Mauricio González Cuervo. En: http://www.corteconstitucional.gov.co/RELATORIA/2013/C-100-13.htm

Corte Constitucional. Sentencia C-072; Exp. D-9733, 4 de febrero de 2014. M.P.: Alberto Rojas Ríos. En: http://www.corteconstitucional.gov.co/relatoria/2014/C-072-14.htm

Corte Constitucional. Sentencia C-123; Exp. D-9700, 5 de marzo de 2014. M.P.: Alberto Rojas Ríos. En: http://www.corteconstitucional.gov.co/relatoria/2014/c-123-14.htm

Ministerio de Transporte. MT-1350-2-49394 (4 de octubre de 2006). En: file://C:/Users/ usuario/Downloads/Concepto_0658.pdf

Ministerio de Transporte. Resolución 266 (16 de febrero de 1999). Por la cual se aprueba la Autoridad Única de Transporte para la administración del Sistema de Servicio Público Urbano de Transporte Masivo de Pasajeros para Santa Fé de Bogotá. En: http://www. alcaldiabogota.gov.co/sisjur/normas/Norma1.jsp?i=29060

Decreto 170 (5 de febrero de 2001). Por el cual se reglamenta el servicio público de transporte terrestre automotor colectivo metropolitano, distrital y municipal de pasajeros, Diario Oficial, n. ${ }^{\circ} 44318$.

Decreto 171 (5 de febrero de 2001). Artículo 22.

Decreto 1079 (26 de mayo de 2015). Por medio del cual se expide el Decreto Único Reglamentario del Sector Transporte, Diario Oficial, n. ${ }^{\circ} 49523$.

Decreto 172 (5 de febrero de 2001). Por el cual se reglamenta el Servicio Público de Transporte Terrestre Automotor Individual de Pasajeros en Vehículos Taxi, Diario Oficial, n. ${ }^{\circ} 44318$.

Decreto 175 (5 de febrero de 2001). Por el cual se reglamenta el Servicio Público de Transporte Terrestre Automotor Mixto, Diario Oficial, n. ${ }^{\circ} 44318$.

Decreto 087 (17 de enero de 2011). Por el cual se modifica la estructura del Ministerio de Transporte, y se determinan las funciones de sus dependencias. Diario Oficial.

Decreto 1079 (26 de mayo de 2015). Por medio del cual se expide el Decreto Único Reglamentario del Sector Transporte, Diario Oficial, n. ${ }^{\circ} 49523$. 